\title{
Transitions in the Early Upper Palaeolithic: An Examination of Lithic Assemblages on the Musashino Upland, Tokyo, Japan
}

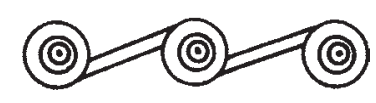

TAKUYA YAMAOKA

\section{INTRODUCTION}

The MUSAShino UPLAND is a part of the south Kanto Plain around Tokyo, in eastcentral Japan. In 1970s, the large-scale excavation of Palaeolithic sites was begun in this region in advance of other regions in the Japanese Islands, with more than 200 Upper Palaeolithic sites excavated since then. Almost all of those excavations were salvage excavations in response to various industrial developments in and around the city of Tokyo. Among them, more than 60 sites have yielded cultural horizons belonging to the Early Upper Palaeolithic (EUP) (Hidai 2000).

A cultural chronology has been established both based on stratigraphic analysis and techno-morphology of stone tools by taking advantage of the thick Pleistocene deposit in which Palaeolithic assemblages were deposited. A chronology of the EUP in this region has been regarded as a standardized one throughout the Japanese Islands since the work in the region brought prominent discoveries earlier than the other regions in Japan. Until the beginning of the 1990s, Palaeolithic archaeologists in Japan focused on qualitative analysis of EUP assemblages that employed stone tool typology using techno-morphological traits. The studies of changes in reduction technologies and morphologies among EUP lithic assemblages have provided a basis framework of cultural chronologies for current EUP research in Japan (Lithic Industries Study Society 1991; Sato 1992).

Despite the efforts of these previous studies, it is obvious that there are some weaknesses in current discussions of changes in lithic assemblages. First, research on Upper Palaeolithic assemblages has largely advanced exclusively based on the samples from the Japanese Islands, with little attempt toward comparisons with Upper Paleolithic evidence elsewhere. Second, most of the discussions have relied on the assumption of cultural continuities during the Upper Palaeolithic. Third, researchers tend to examine only the production of formal tools in discussing changes in lithic assemblages. Because of these research biases, technological and morphological changes in EUP lithic assemblages have been mainly explained as the development (i.e., increasing 
sophistication of tool-making skills) of blade technology and methods of formal tool production. Therefore, characteristics of Japanese EUP assemblages are rarely discussed on a global scale, although the abundant archaeological data of the Japanese EUP has the potential for broad significance in understanding the emergence and dispersal of modern humans in eastern Eurasia.

The goal of this article is to discuss the transitional processes during the EUP, based on a quantitative study of EUP assemblages in the Musashino Upland, outlining their characteristics and their significance in terms of illuminating related changes in foraging strategies and technological organization in the EUP.

\section{BACKGROUND ON EUP RESEARCH ON THE MUSASHINO UPLAND}

The Musashino Upland is located in the southwest Kanto Plain, the largest plain in the Japanese Islands. The study of the formation process of the Musashino Upland has a long research history and there are a lot of previous studies. I present an outline of these studies as background for the EUP archaeological research discussed here, particularly bringing recent references to bear on this issue (Hidai 2000; Kaizuka et al. 2000).

"Musashino" extends from the Tama River in the south, to the Ara River in the northeast, and to the Iruma River in the northwest; all uplands higher than the flatlands along these rivers are known as the Musashino Upland. The Musashino Upland consists of several terraces that were formed by changes in the course of the Tama River, and the lower levels of deposits in those terraces are often river deposits left by the old Tama River. Therefore, the Musashino Upland represents not only a series of river terraces that were eroded by the Tama River, but also distinct alluvial fans with river deposits left by the Tama River.

The Musashino Upland is generally divided into four terraces, defined in terms of dates of formation, including (in order of elevation and antiquity, from oldest to most recent): the Tama Terrace, the Shimosueyoshi Terrace, the Musashino Terrace, and the Tachikawa Terrace. In general, these terraces were eroded by stream channels in response to sea level changes and the effects of tectonic upheavals. The Tama Terrace, Musashino Terrace, and Tachikawa Terrace are river terraces, while Shimosueyoshi Terrace is a coastal terrace.

The Musashino Upland is located downwind of volcanoes that supplied volcanic ash. The thick sediments covering the terraces of the Musashino Upland are known as the "Kanto Loam," and the thickness of terrace deposits varies depending on histories of terrace formations, which have been securely cross-dated by tephras. Stratigraphic divisions using tephro-chronology allowed researchers to conduct systematic comparisons of terraces that in turn allowed determinations of the geographic distributions of terraces on the Musashino Upland. The lands lower than the Tachikawa Terrace were formed during the Holocene, and therefore the Kanto Loam had not accumulated on them.

The Tama Terrace, initially formed during the early Middle Pleistocene, now remains on the hills on the edge of the Musashino Upland. The Shimosueyoshi Terrace, formed by the Shimosueyoshi transgression during the last interglacial period as water inundated the Kanto Plain as the sea level rose, is distributed mainly in the eastern part of the Upland. The Musashino Terrace is most extensively distributed on the Upland, formed during the period between the onset of early Stage 3 and the end of Stage 5e, when the sea level gradually lowered, which increased accumulation of river deposi- 
tion and induced recession of mouths of the Tama River. The Tachikawa Terrace was formed between late Stage 3 and Stage 2, and it is mainly distributed on the southern edge of the Musashino Upland.

Palaeolithic sites in general are mostly located along several drainage basins, and have been found on the Tama, Shimosueyoshi, Musashino, and Tachikawa terraces. Almost all EUP sites, in particular, are located on the Musashino Terrace, although recently a few sites have been excavated on the Tachikawa Terrace. Figure 1 illustrates the distribution of EUP sites mentioned in the text. As shown in Figure 1, sites no. 6 and no. 32 are located on the Tachikawa Terrace, while the remaining sites are located on the Musashino Terrace.

The aeolian deposits of Kanto Plain, accumulated since the beginning of the Middle Pleistocene, is called Kanto Loam. It is a generic name of a series of deposits made up of primary tephra layers, second deposits of tephra, aeolian dust (or "loess" from China), fine sand blown from river terraces, and weathered materials. The Kanto Loam is divided into four stratigraphic units whose ages of formation roughly correspond to the topographic divisions of the terraces: from Tama at the bottom, to Shimosueyoshi, Musashino, and Tachikawa loams. The Tachikawa Loam is the uppermost deposit among the four divisions, and abundant Palaeolithic artifacts have been found exclusively from this formation, while artifacts have never been found in the Musashino Loam on the Musashino Upland.

Studies of the deposits of Tachikawa Loam in the context of archaeological investigations started in the 1970s and researchers have established a total of 12 strata in archaeological contexts (Akazawa et al. 1980). From the earliest Stratum I at the top to Stratum XII at the bottom, these stratigraphic divisions in the Tachikawa Loam were mainly based on differences in matrices, including color, texture, and inclusions of sediments. Stratum I and II are black to dark brown Holocene humus deposits, which have yielded a Holocene archaeological record, while Late Pleistocene archaeological deposits correspond with strata III to X in the Tachikawa Loam.

Stratum III, the uppermost stratum of the Tachikawa Loam, is a soft deposit with yellowish brown color, in contrast to all of the underlying hard deposits. Stratum IV is a brown deposit and StratumV, a dark brown deposit, also known as the Black Band I (buried paleosol). Stratum VI is a yellowish brown deposit and the widespread, AiraTn marker tephra (AT; c. 25,000-24,000 B.P.) (Japan Association for Quaternary Research 2000:42-43) is normally found in this stratum. This key tephra is distributed over a large area, covering most of the Japanese Islands, as well as the Korean Peninsula, a part of eastern China, and southern Primorye in the Russian Far East. Stratum VII and Stratum IX are dark brown deposits, also known as the Black Band II (buried paleosol). Stratum VIII, a yellowish brown deposit, can be sometimes found between Stratum VII and Stratum IX. The underlying deposit of Stratum IX to the bottom of Tachikawa Loam is a yellowish brown deposit. Within the deposit of Stratum XI, a large amount of reddish scoria is contained, which divides Stratum X and Stratum XII.

As noted above, Palaeolithic artifacts are found from Stratum III to Stratum X in the Tachikawa Loam. Lithic assemblages from the lower strata (from strata VI to X) belong to the EUP. The assemblages from Stratum X are regarded as the initial EUP in this region. Artifacts have never been found from deposits below Stratum XI on the Musashino Upland. The date of EUP assemblages in the Musashino Upland is estimated to be around 40,000 to $28,000 \mathrm{cal}$ B.P. AT tephra is also identified in a marine 


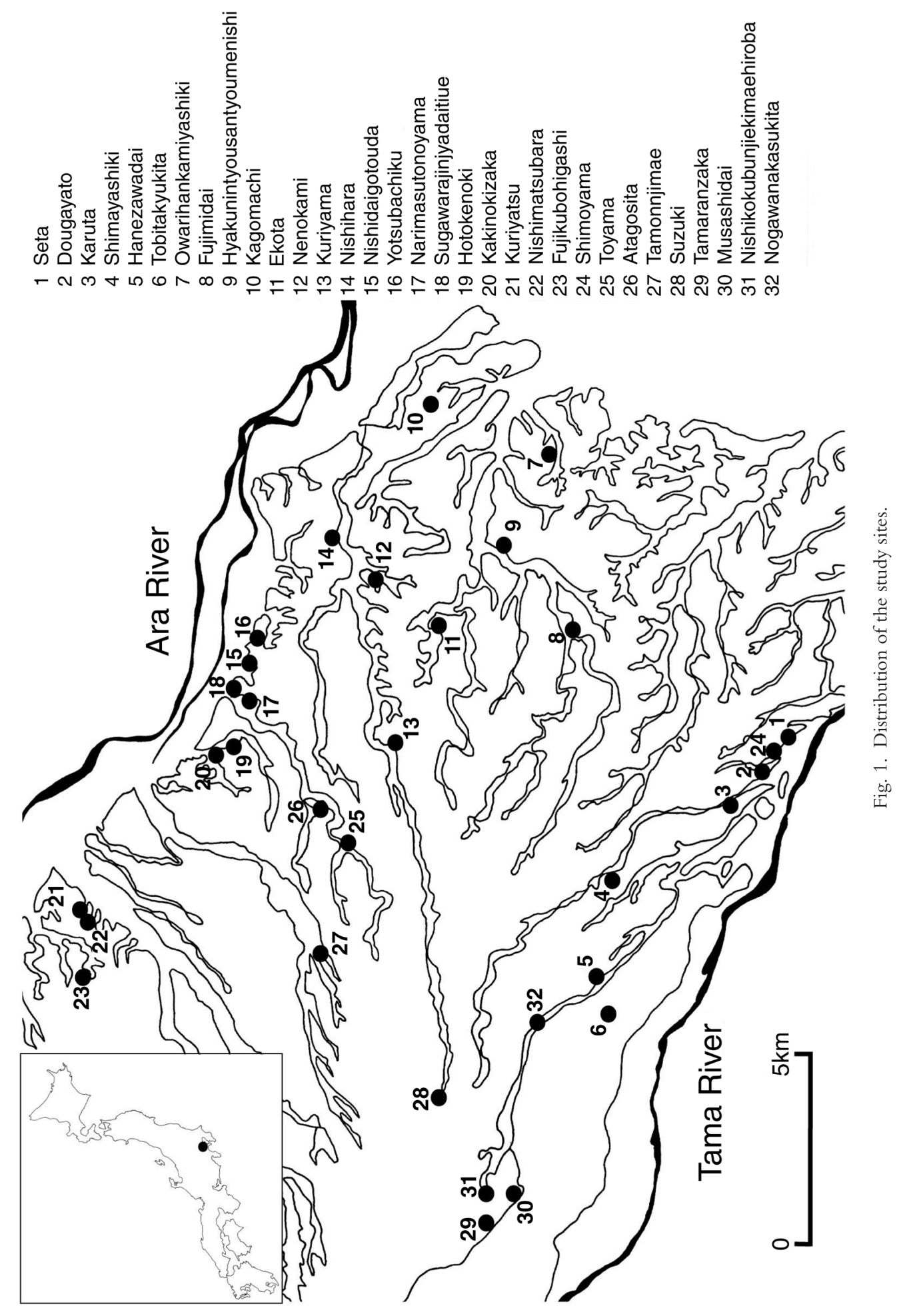


core of the Japan Sea (Aoki and Arai 2000). It coincides well with the transition from Stage 3 to Stage 2 and the estimated date is about 29,000-28,000 cal B.P. based on the oxygen isotope data from the GISP2 (Machida 2005). The date of assemblages from Stratum VI are expected to be younger than that of AT tephra, because Stratum VI seems to have begun to accumulate after the eruption of AT. On the other hand, Stratum X is likely to have accumulated after around 40,000 B.P., using the age of upper (AT) and lower (SI: 50,000-47,000) key tephra, given the assumption that the rate of sedimentation was constant (Machida 2005). Reliable AMS dates were obtained from hearths in Stratum X at the open-air site of the Musashidai west location: $29,860 \pm 150$ B.P. (Beta-182638) and $30380 \pm 400$ B.P. (Beta-156135) (Tokyo Metropolitan Archaeological Research Center 2004), although chronometric dates from this stratum on the Musashino Upland are still rare. However, we still need to obtain data to clarify when the earliest Upper Palaeolithic assemblages appeared on the Musashino Upland.

Having provided an overview of the geological contexts, geographic distribution, and chronology of the EUP in the region, the rest of this paper is devoted to discussing innovative changes in lithic raw material utilization and characteristics of initial EUP assemblages through comparisons of lithic raw material selections, core reductions (blade technology), and formal tool production. The results of the analysis will indicate temporal variation in lithic raw material utilization among the cultural periods and its implications for understanding the developing technological and organizational strategies of foragers in the EUP of the Japanese Islands.

\section{THE STUDY ASSEMBLAGES}

The study materials that form the basis for this work are from EUP lithic assemblages on the Musashino Upland (Figs. 1 and 2, Table 1). The units of analysis are concentrations of lithic artifacts that share the same lithic raw materials in an archaeological horizon. Therefore, I include only the excavated sites that yielded data from lithic concentrations in the present analysis. Regarding site stratigraphies and chronologies, I divide EUP lithic assemblages into three sequential periods in order to compare lithic assemblage characteristics (e.g., lithic raw material selections, core reductions, and formal tools production) over time. Period I represents lithic assemblages from Stratum X to the lower level of Stratum IX, Period II contains those from the upper level of Stratum IX to Stratum VII, and Period III contains those from Stratum VI. A total of 71 analytical units (components in assemblages) were utilized in the analysis: Period I $(\mathrm{n}=18)$, Period II $(\mathrm{n}=31)$, and Period III $(\mathrm{n}=22)$.

\section{RESEARCH METHODS}

To illuminate lithic raw material utilization during the EUP, I chose to examine three techno-morphological variables in the lithic assemblages: 1) the selection of lithic raw materials, 2) core reductions, mainly on blade technology, and 3) formal tool productions.

\section{Selection of Lithic Raw Materials}

The selection of lithic raw materials among the periods is compared through counts and weights of obsidian and the other lithic materials. Obsidian is an exotic lithic material on the Musashino Upland, since obsidian sources are located outside the area 


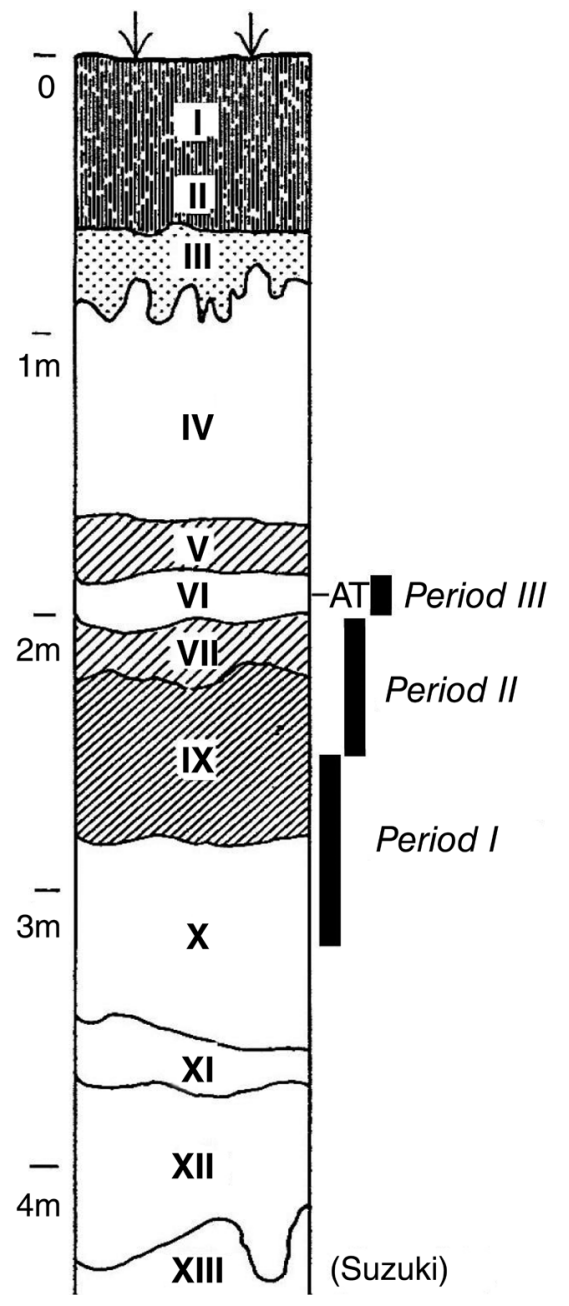

Fig. 2. Stratigraphic sequence of Tachikawa Loam.

defined as the Musashino Upland, and distances between EUP sites and the closest sources measure more than $80 \mathrm{~km}$. Researchers have emphasized the significant phenomenon that obsidian is increasingly utilized for manufacturing chipped stone artifacts at the final EUP in the southern Kanto Plain (Inada 1984; Kanayama 1990; Lithic Industries Study Society 1991). However, in these previous studies, quantification of lithic artifacts is simply based on raw counts of artifacts. Employment of raw numbers of lithic artifacts is not sufficient to evaluate diachronic changes in lithic raw material utilization in the EUP since this method makes no distinction between tools and lithic debris of different sizes, making comparisons between sites with different assemblage composition difficult. Therefore, both counts and weights of artifacts are examined in the present study.

\section{Core Reductions}

Classes of core reduction are examined on blank forms of chipped stone tools with refitted specimens on which blades and elongated flakes were manufactured. 


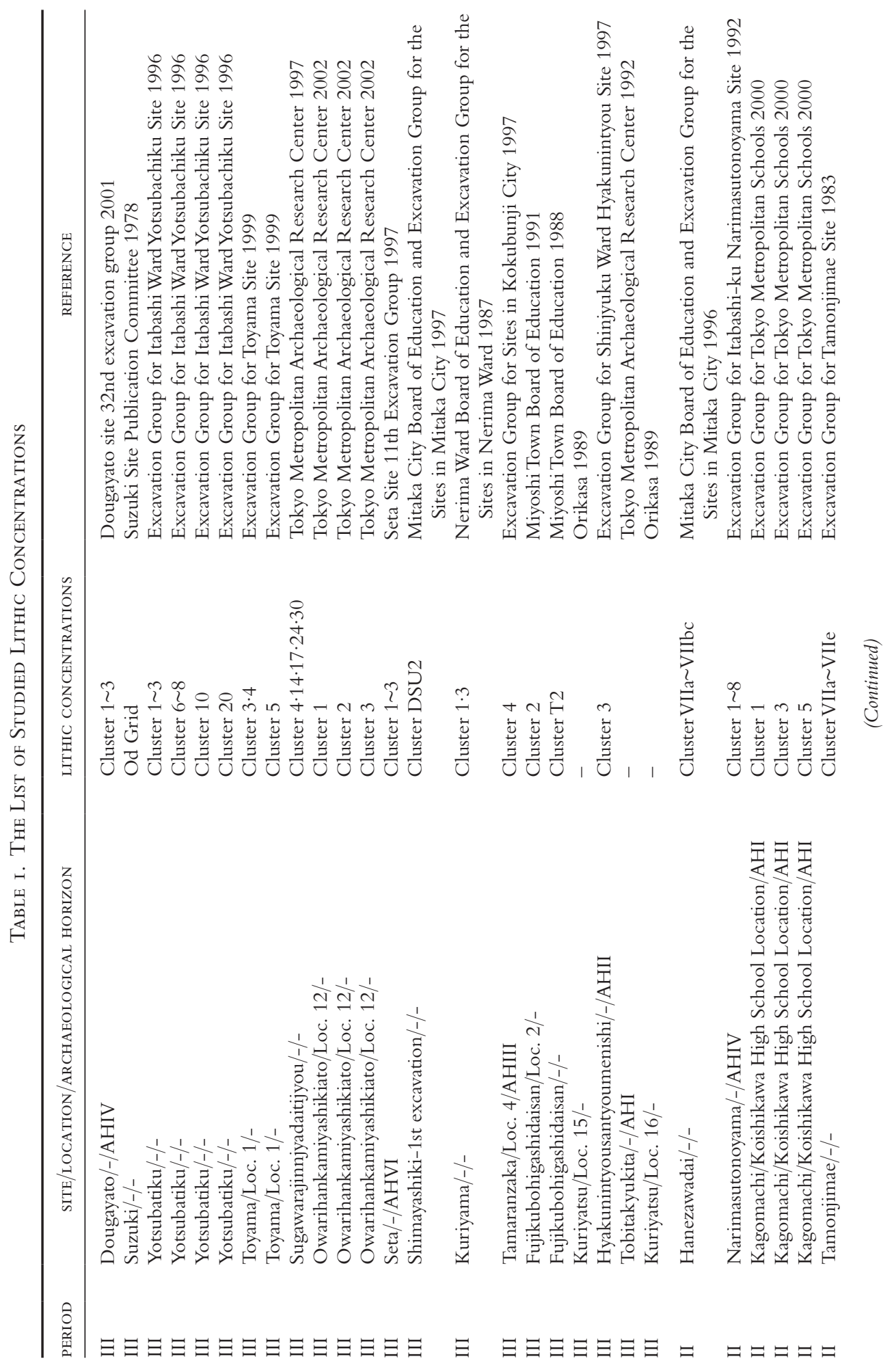




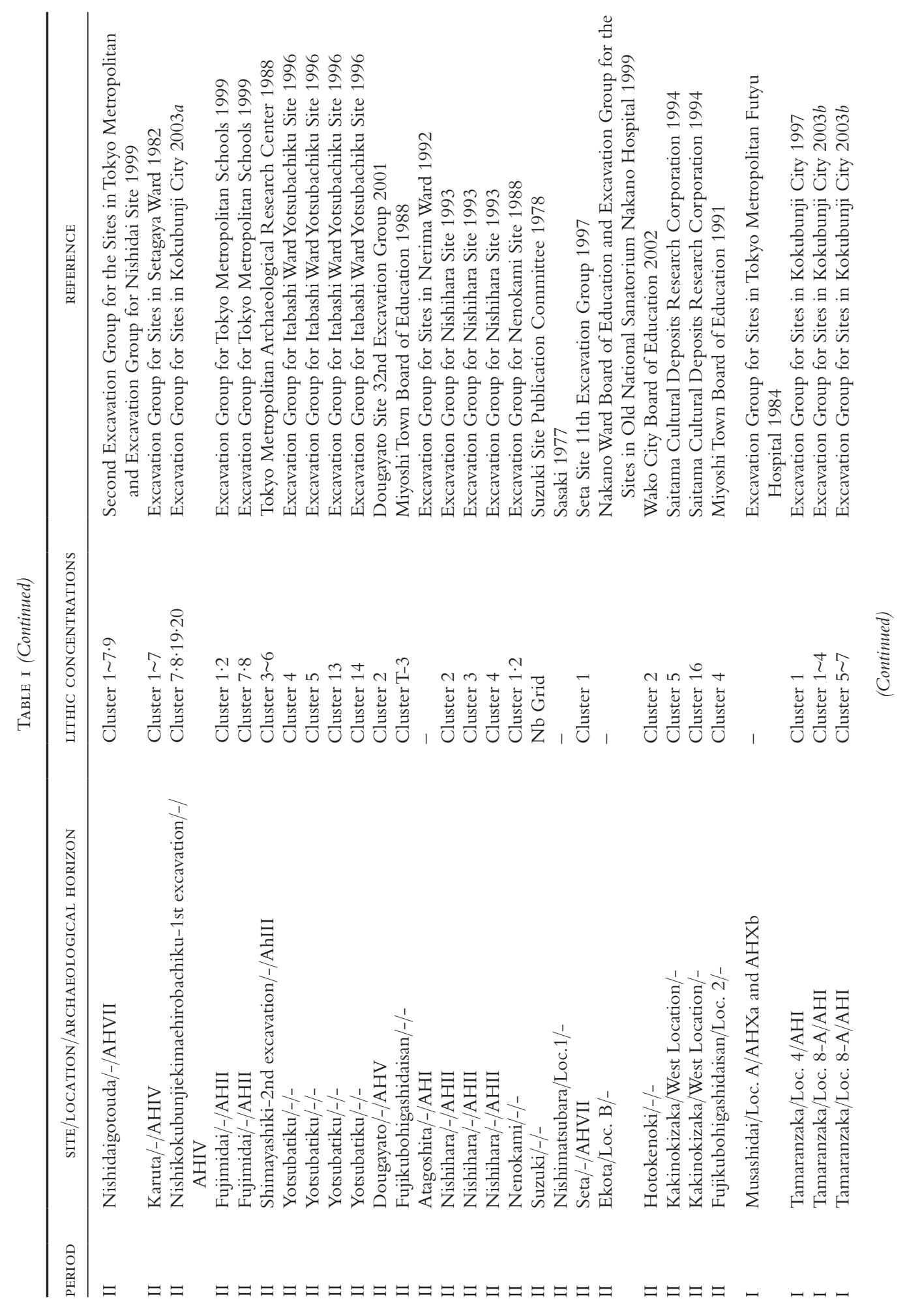




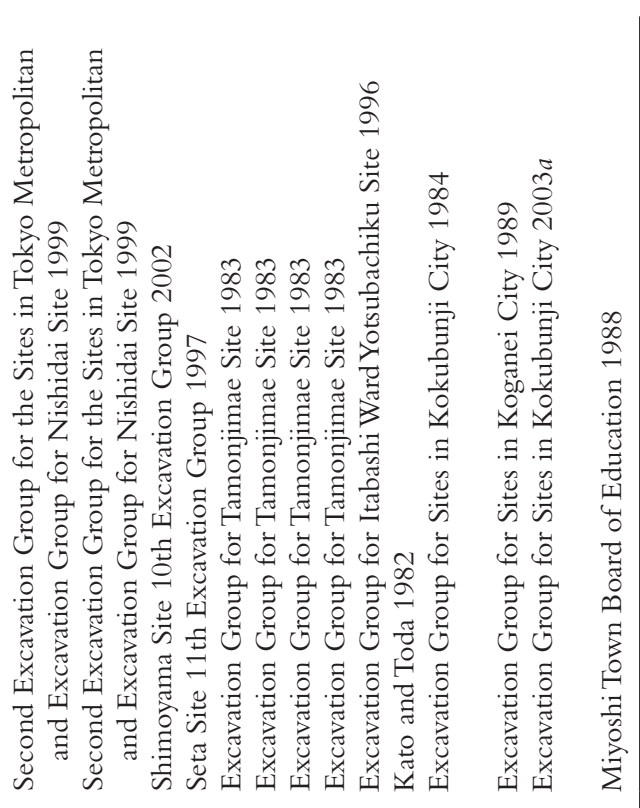

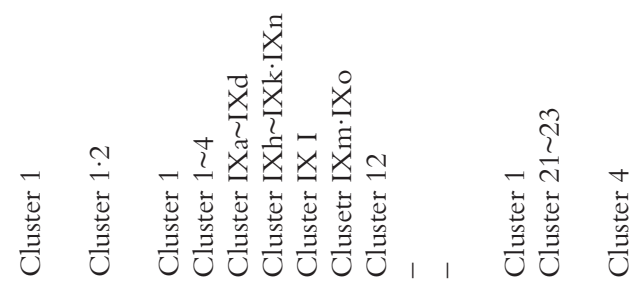

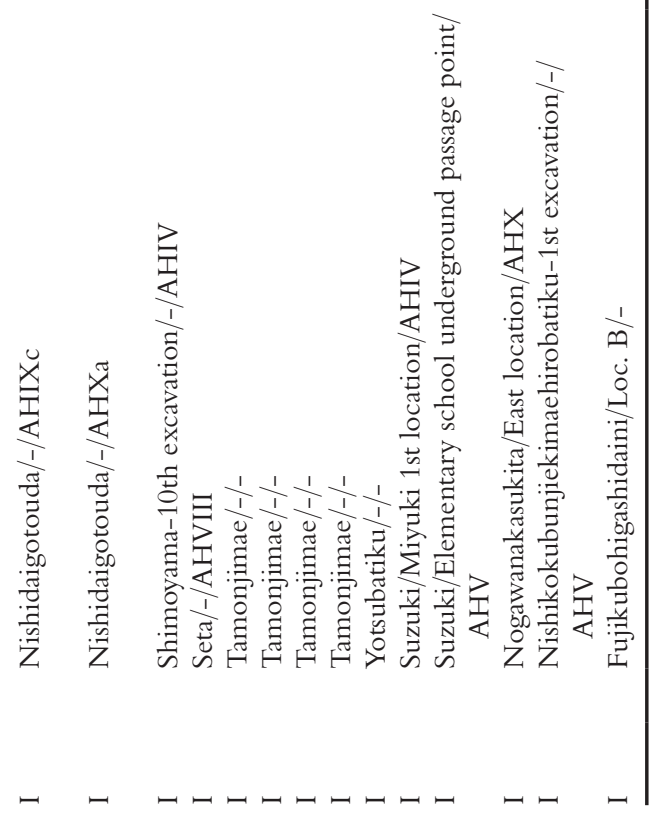


Diachronic changes in core reduction methods have been discussed among Japanese Palaeolithic archaeologists (e.g., Lithic Industries Study Society 1991), who are mainly concerned with the blade technology because temporal variability is prominent (Fujiwara 1983; Kakubari and Fujinami 1986, 1987; Okumura 1987). Examinations of refitted blades and cores, and ratio of blades to flake blanks among chipped stone tools are conducted to evaluate variation in EUP blade technology.

\section{Formal Tool Production}

Formal tool production is examined by analyses of both formal and informal flaked tools, as well as adzes (with a ground edge). Study of the formal flaked tools has been a central theme among researchers of the Japanese EUP (Lithic Industries Study Society 1991). Variability in formal flaked tools through time and across space has been mainly examined by qualitative analysis of formal tools. However, I argued that conventional typology of formal flaked tools is not appropriate due to their vague definitions (Yamaoka 2004, 2006a), and in the current research, classes of formal flaked tools are redefined using a more rigorous method (Yamaoka 2006a). The frequency of formal and informal flaked tools is quantitatively compared between obsidian and the other material types.

Ground-edge adzes have been found since the 1970s in the Japanese EUP assemblages. Because of their rarity in the Early Upper Palaeolithic industries of the Old World, their presence has been regarded as a peculiar cultural trait in the Japanese Islands (Toda and Excavation Group for Suzuki Site 1976). Given the distinctiveness of their presence in Japan, I collected information on all specimens of ground-edge adzes in EUP assemblages on the Musashino Upland to examine relations with changes in the previously-discussed variables (i.e., selection of lithic raw materials and core reductions, as well as formal and informal flaked tool production).

\section{THE SELECTION OF LITHIC RAW MATERIALS}

Table 2 shows the mean and total counts (n) of lithic artifacts of all material types from the study units, the mean and total weights (g) of lithic artifacts from the study units, as well as the average weights of lithic artifacts in each period as expressed by the ratio

Table 2. The Number and the Weight of Lithic Artifacts

\begin{tabular}{|c|c|c|c|c|c|c|c|}
\hline & \multicolumn{3}{|c|}{ ALL LITHIC ARTIFACTS } & \multicolumn{4}{|c|}{ OBSIDIAN } \\
\hline & $\mathrm{N}$ & G & $\mathrm{G} / \mathrm{N}$ & $\mathrm{N}$ & $\%$ & G & $\%$ \\
\hline \multicolumn{8}{|c|}{ Period III } \\
\hline Mean & 197 & 578.9 & 5.2 & 159 & $69.1 \%$ & 184.3 & $54.8 \%$ \\
\hline Total & 4337 & 12736.7 & 2.9 & 3499 & $80.7 \%$ & 4055.6 & $31.8 \%$ \\
\hline \multicolumn{8}{|c|}{ Period II } \\
\hline Mean & 193 & 2773.0 & 13.6 & 61 & $31.5 \%$ & 69.2 & $13.9 \%$ \\
\hline Total & 5988 & 72096.7 & 12.0 & 1882 & $31.4 \%$ & 1798.7 & $2.5 \%$ \\
\hline \multicolumn{8}{|c|}{ Period I } \\
\hline Mean & 263 & 4989.6 & 28.0 & 25 & $9.1 \%$ & 37.3 & $3.9 \%$ \\
\hline Total & 4733 & 89813.3 & 18.8 & 457 & $9.7 \%$ & 633.4 & $0.7 \%$ \\
\hline
\end{tabular}


of $\mathrm{g} / \mathrm{n}$, again including all raw material types. The percentage of obsidian relative to all lithic artifacts shows the relative frequency of obsidian use through various temporal phases. A remarkable increase in proportion of obsidian use among the assemblages from Period I to Period III is observed, supporting the previous observations of this trend (Kanayama 1990; Lithic Industries Study Society 1991). While the rate of increase from Period I to Period II is not dramatic, obsidian use was gradually increasing. Table 2 shows the relationships between classes of raw materials and mean weight of lithic artifacts among the study units. Generally, the mean weight of lithic artifacts, represented by " $\mathrm{g} / \mathrm{n}$ " for "all lithic artifacts," are extremely light in the study units where the proportions of obsidian artifacts in the assemblages are high. This is because many small flakes are made from obsidian, while large flakes and cores are few. A clear contrast is that mean weights of the assemblages in Period I are heavier, while those of Period III are lighter. Proportions of obsidian are high in the assemblages of Period III. There are some assemblages that have quite large mean weights among those of periods I and II, while mean weights of the assemblages of Period III are generally lighter. Most of the non-obsidian lithic raw materials in the assemblages of periods I and II are locally available low-quality chert, of which larger cores and flakes were abundantly manufactured. In contrast, non-obsidian raw materials in the assemblages of Period III include exotic hard shale and black shale, which are characteristically high quality. Similar to obsidian artifacts, lithic artifacts made of exotic shale rarely have larger cores and flakes. These observations suggest that high-quality materials were frequently utilized for core reductions during Period III.

\section{CORE REDUCTION}

Figure 3 illustrates refitting specimens in which blades and elongated flakes were manufactured. The refitted specimens similar to the illustrated specimens are ubiquitously identified in the assemblages of Period III. In most cases, platform and fringe trimmings are identified, and blade cores are included in refitted specimens. Traces of core rejuvenations are sometimes observed. On the other hand, among the assemblages of periods I and II, few refitted specimens have blades. The platform preparation and core rejuvenation are seldom found, and blade cores are rare.

High-quality raw materials were frequently found among the refitted specimens, including blades and elongated flakes. Particularly, in those of periods II and III, the majority of the refitted specimens are obsidian, while the size of refitted specimens becomes larger in Period III. Thus, blade technology came to be more dominant, coupled with high-quality and large materials, during Period III.

Table 3 shows diachronic variability of blade blank tools in formal and informal flaked tools. It displays mean and total of the frequencies of blade blank tools in the study units. A remarkable increase in use of blade blank tools from Period I to Period III is observed. This change suggests that blade technology came to be a principal method of core reductions in Period III.

\section{FORMAL FLAKED TOOLS AND INFORMAL FLAKED TOOLS}

Figure 4 shows the definition of formal flaked tools in this study, while Table 4 lists the number of flakes containing flaked tools (longer than $2 \mathrm{~cm}$ ), formal flaked tools (types 

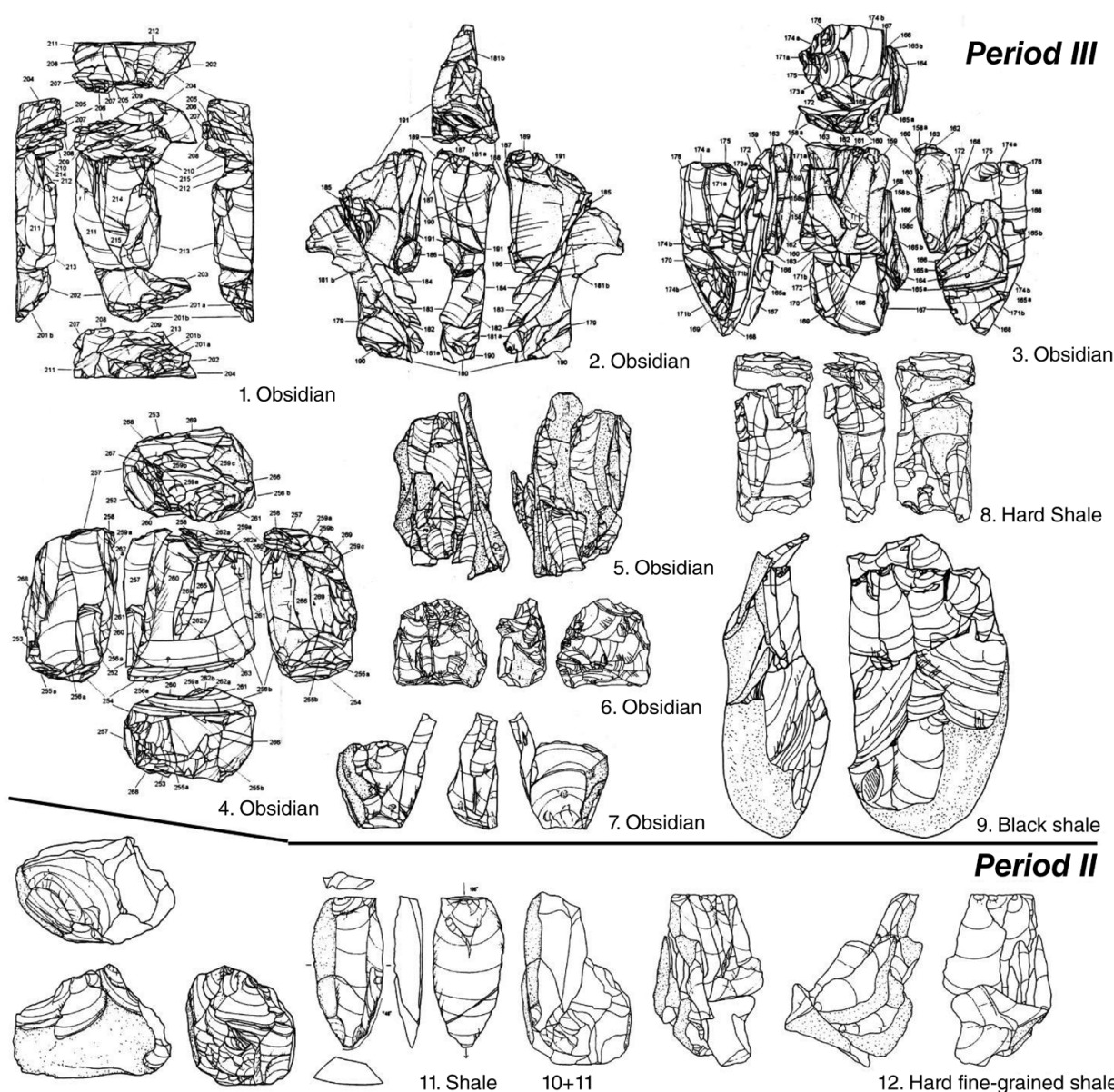

5. Obsidian
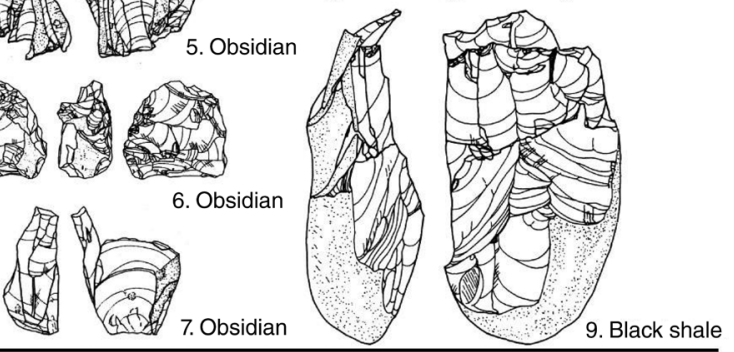

Period II

10. Shale
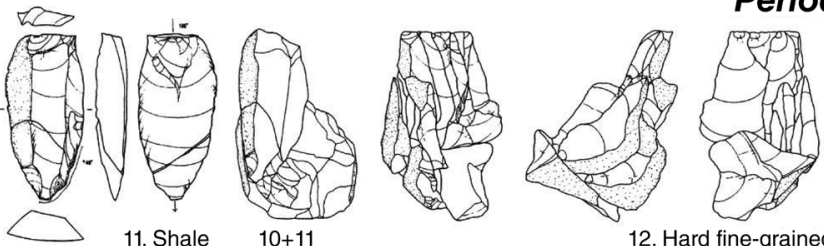

11. Shale

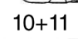

12. Hard fine-grained shale
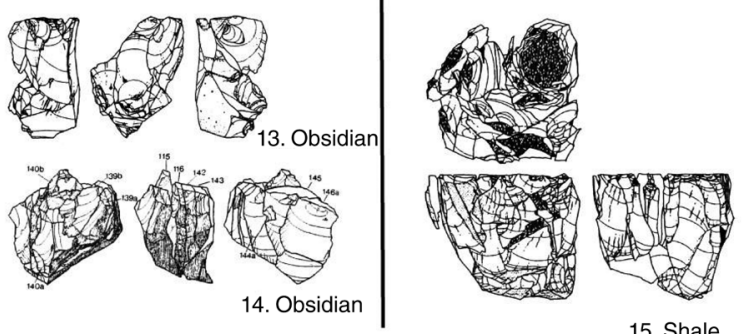

15. Shale

1-4: Dougayato/-/AH IV/Cluster 1-3, 5: Suzuki/-/-/Od Grid,

6: Owarihankamiyasikiato/Loc. 12/-/Cluster 3, 7: Seta/-/AH VI/Cluster 1-3

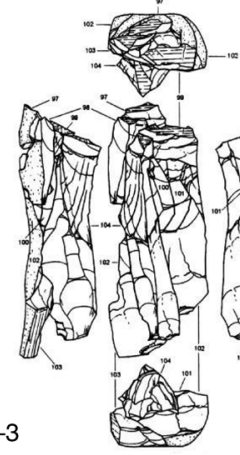

Period I

8: Sugawarajinnjyadaitijyou/-/-/Cluster $4 \cdot 14 \bullet 17 \bullet 24 \bullet 30$, 9: Tobitakyukita/-/AH I,

10 • 11: Nishidaigotouda/-/AH VII/Cluster 1 7 • 9, 12 • 13: Hanezawadai/-/-/Cluster VIla VIIbc

14: Karuta/-/AH IV/Cluster 1 7, 15: Nishikokubunjiekimaehirobatiku-1st excavation/-/AH IV/Cluster 7• 8 • 19 •20,

16: Shimoyama-10th excavation/-/AH IV/Cluster 1

Fig. 3. Reffiting specimens. 
Table 3. The Frequency of Blade Blank Tools in Formal and Informal Flaked Tools

\begin{tabular}{|c|c|c|c|}
\hline \multirow[b]{2}{*}{ LITHIC CONCENTRATIONS } & \multirow{2}{*}{$\begin{array}{c}\text { FORMAL AND INFORMAL } \\
\text { FLAKED TOOLS }\end{array}$} & \multicolumn{2}{|c|}{ BLADE BLANK TOOLS } \\
\hline & & $\mathrm{N}$ & $\%$ \\
\hline \multicolumn{4}{|l|}{ Period III } \\
\hline Mean & & & $34.2 \%$ \\
\hline Total & 203 & 91 & $44.8 \%$ \\
\hline \multicolumn{4}{|l|}{ Period II } \\
\hline Mean & & & $19.5 \%$ \\
\hline Total & 257 & 48 & $18.7 \%$ \\
\hline \multicolumn{4}{|l|}{ Period I } \\
\hline Mean & & & $11.9 \%$ \\
\hline Total & 110 & 6 & $5.5 \%$ \\
\hline
\end{tabular}

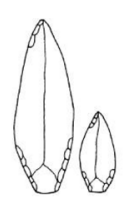

Type A

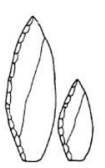

Type B

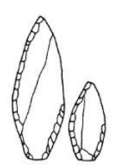

Type C

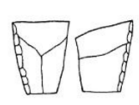

Type D

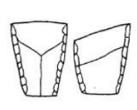

Type E

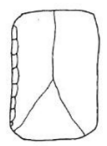

Type G Type H

Type A: a pointed flake that was formed by secondary retouch to the tip and a side of base or both side of bases on a long axis of a blank

Type B: a pointed flake that was formed by secondary retouch to a side of edge on a long axis of a blank

Type C: a pointed flake that was formed by secondary retouch to both side of edges on a long axis of a blank

Type D: a flake with flat or diagonal non-retouched edge that was formed by secondary retouch to a side of edge on a long axis of a blank

Type E: a flake with flat or diagonal non-retouched edge that was formed by secondary retouch to both sides of edge on a long axis of a blank

Type F: a penpoint-shaped flake that was formed by secondary retouch to both sides of base on a long axis of a blank

Type G: a flake with secondary retouch of more than $1 / 2$ length on a long axis of a blank

Type $\mathrm{H}$ : a flake with abrupt secondary retouch on an extremity of a blank

Fig. 4. Definitions of formal flaked tools.

A-H), and informal flaked tools (marginally retouched flakes except types A-H). The numbers in parentheses designate counts of obsidian specimens. These data suggest that the composition of classes of formal flaked tools (i.e., types A-H) changed through time. Amounts of types A-F varied across time, while types $\mathrm{G}$ and $\mathrm{H}$ are, by and large, evenly distributed in the assemblages of all periods. In Period I, types D, E (trapezoids), and F are notably found. On the other hand, in the assemblages of Period III, types A, B, and C (pointed blades and flakes) are found in significant quantity. The assemblages of Period II have moderate composition of formal flaked tools.

Using the data from Table 4, Table 5 was created to exhibit the mean and total of the frequencies of formal and informal tools on flakes longer than $2 \mathrm{~cm}$, and flaked tools in the all study units. The frequencies of obsidian formal and informal flaked tools are generally high in the assemblages of all periods. But in considering "all" lithic raw materials, the analysis confirms an overall increase in the frequencies of formal and informal flaked tools. This trend is accordant with an increase in the percentage of obsidian artifacts from Period I to Period III (Table 2). However, percentages of formal and informal flaked tools in "the other" category of raw materials also increase from Period I to Period III. This suggests an expansion of formal flaked tool 


\section{Formal flaked tools}
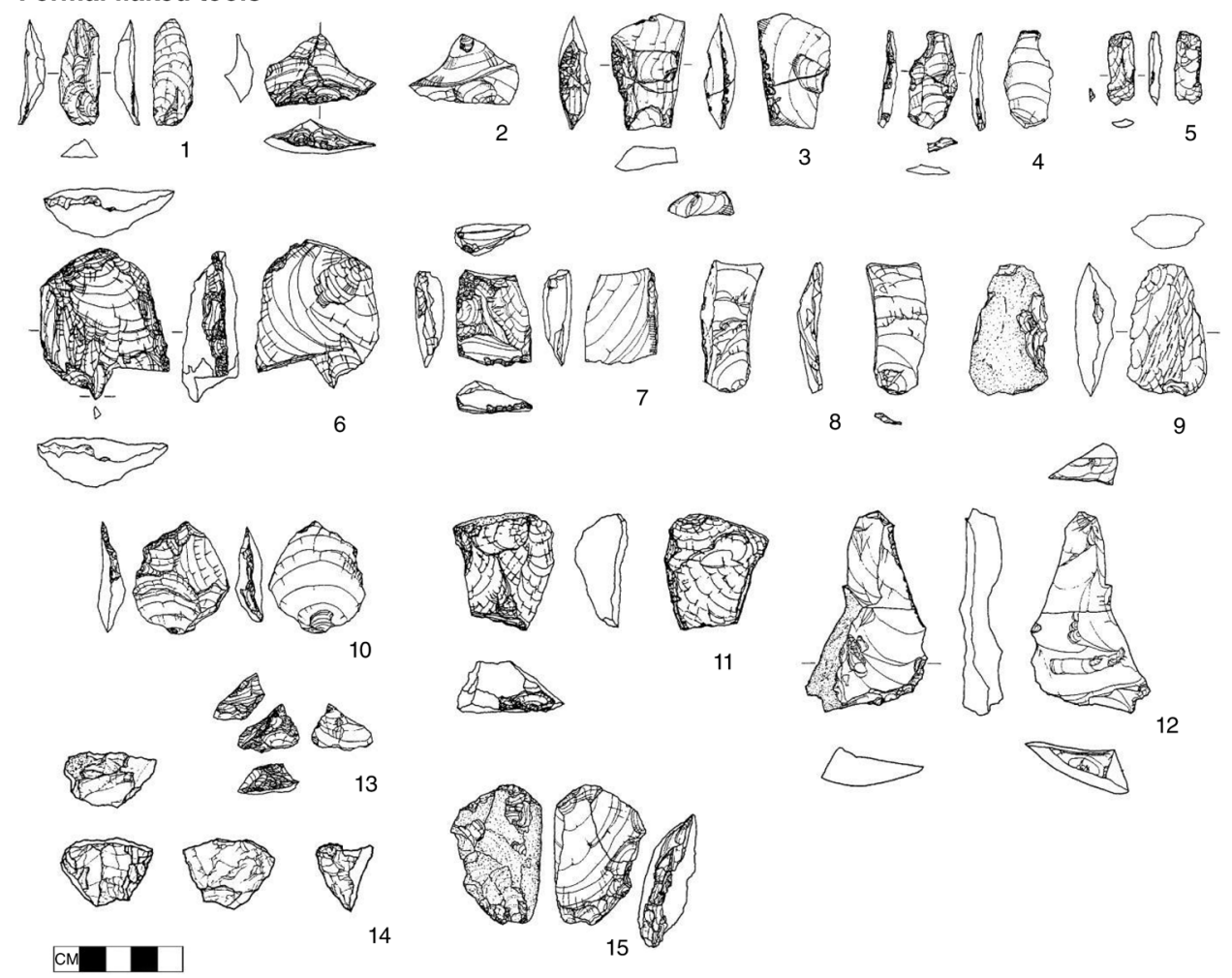

11
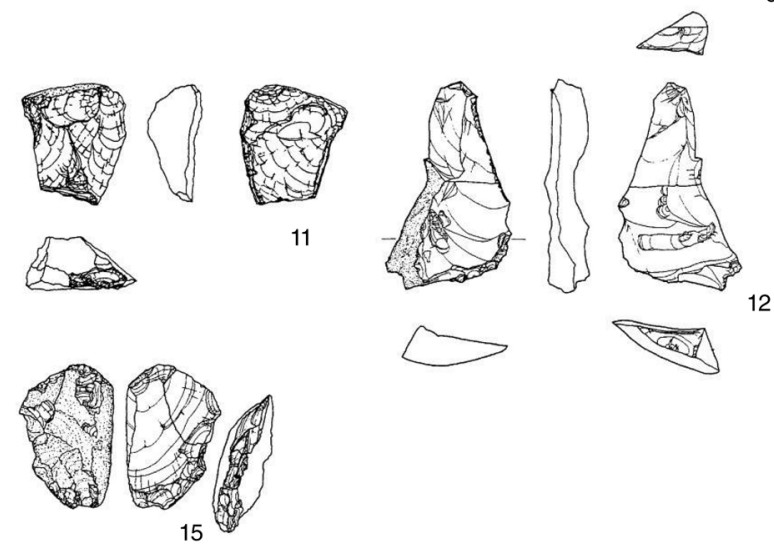
2

Musashidai Loc. A AH Xa and AH Xb

(Excavation group for the sites in Tokyo Metropolitan Futyu Hospital 1984)

Fig. 5a. Formal tools (formal flaked tools) from a representative site in Period I (Scale $\frac{1}{4}$ ).

production, as well as increasing use of high-quality materials, both obsidian and other classes of materials, in Period III.

\section{ADZES}

Adzes are either unifacially or bifacially shaped core tools having a convex cross section, some with ground edges. Table 6 shows the number of adzes from EUP assemblages of Musashino Upland. Areas in Table 6 with a gray background represent the sites that contain the study unit of Table 1. They are notably found in Stratum X to lower Stratum IX, while they are seldom found in levels above lower Stratum IX. The frequencies of occurrence of adzes roughly coincide with the change of formal flaked tools composition from Period I to Period II. The early occurrence of adzes (mostly yielded from the vicinity of the bottom of the Tachikawa Loam) have been recognized by Palaeolithic archaeologists since the beginning of EUP research in the 1970s (Toda and Excavation Group for Suzuki Site 1976), and the present data on these newly discovered specimens further supports this observation. The lithic raw materials preferentially used for adzes are tuff and sandstone, which are distinct from those of formal flaked tools. 


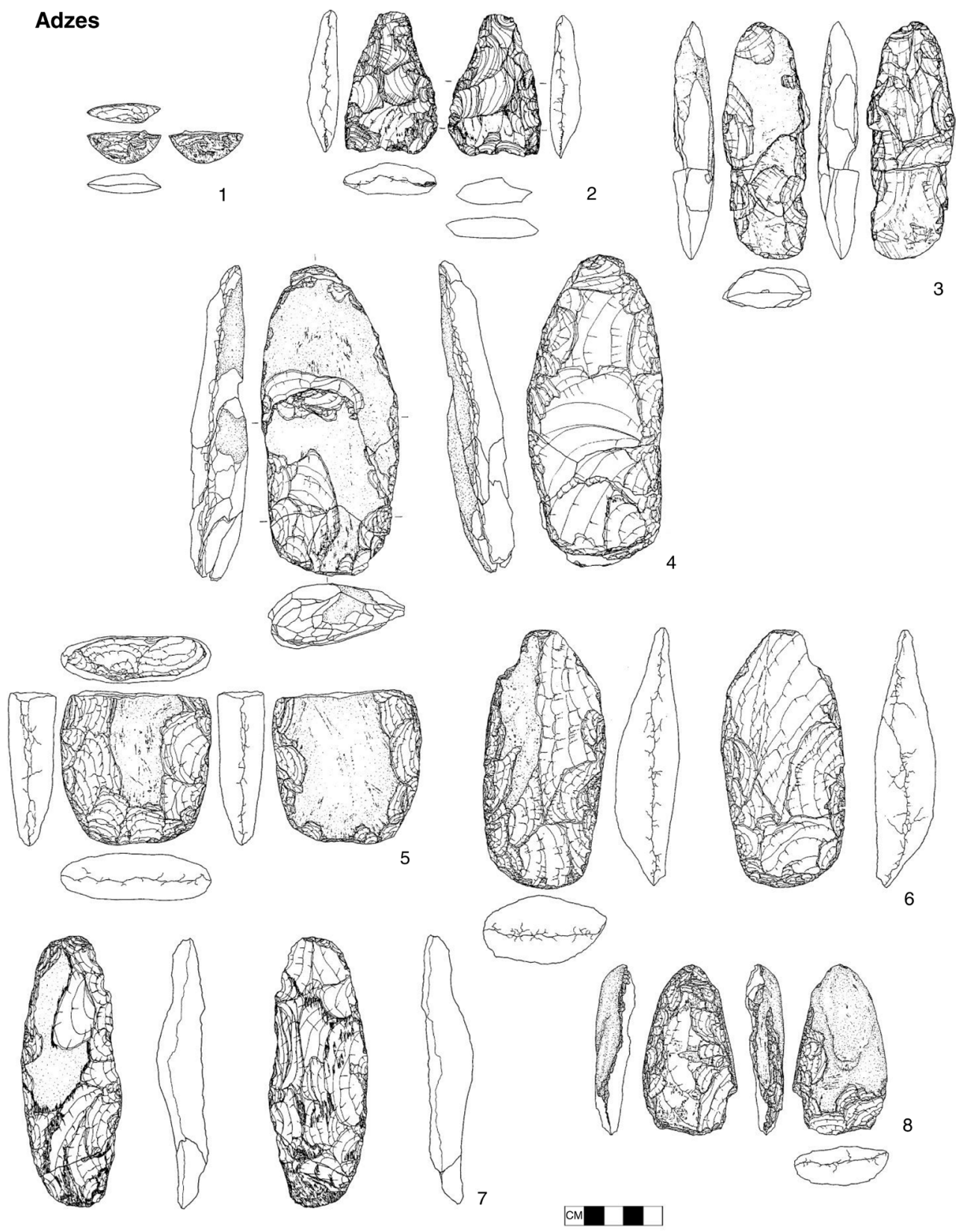

Musashidai Loc. A AH Xa and AH Xb

(Excavation group for the sites in Tokyo Metropolitan Futyu Hospital 1984)

Fig. 5b. Formal tools (axe-shaped core tools) from a representative site in Period I (Scale $\left.\frac{1}{4}\right)$. 


\section{Formal flaked tools}
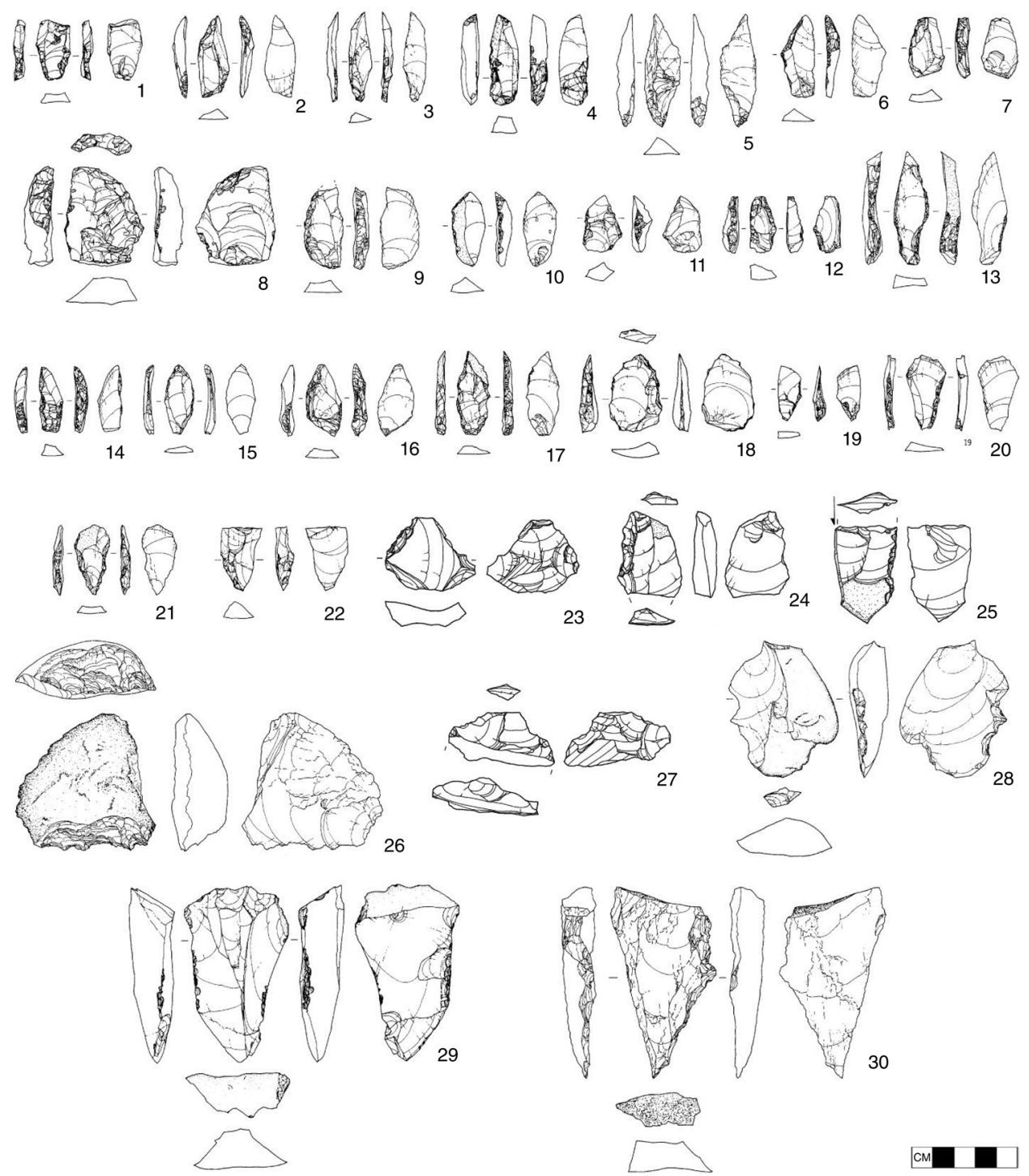

Hanezawadai Cluster VIla-VIlbc

(Mitaka City Board of Education and Excavation group for the sites in Mitaka City 1996)

Fig. 6. Formal tools (formal flaked tools) from a representative site in Period II (Scale $\frac{1}{4}$ ).

\section{DISCUSSION}

The lithic data presented in the current study show two remarkable characteristics in all periods: (1) high-quality lithic raw materials were used particularly for those of the studied refitted specimens on which blades and elongated flakes were manufactured, and (2) formal and informal flaked tools are made frequently from high-quality lithic materials (e.g., obsidian). These observations allow us to suggest that high-quality 
Formal flaked tools
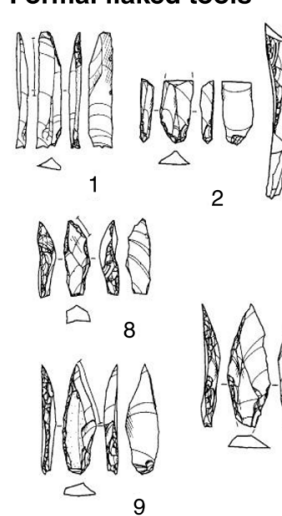

Dougayato AH IV Cluster 1-3 (Dougayato site 32nd excavation group 2001)

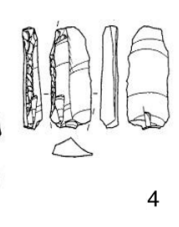

3
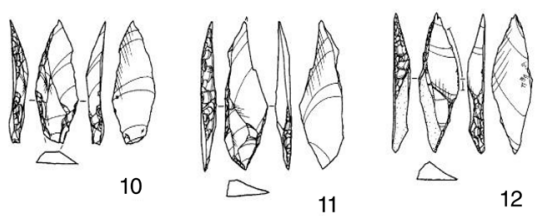

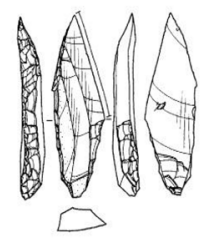

6
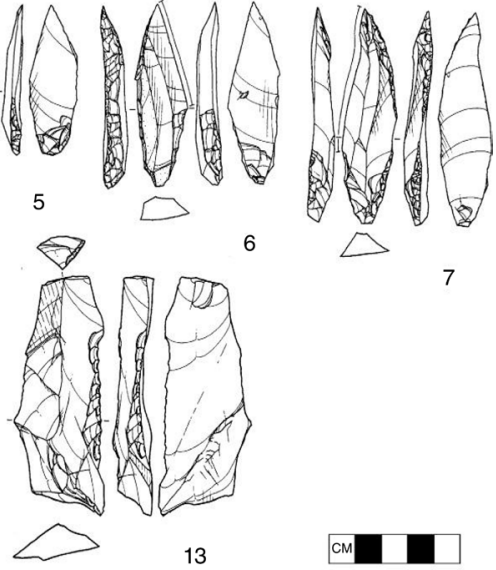

Fig. 7. Formal tools (formal flaked tools) from a representative site in Period III (Scale $\frac{1}{4}$ ).

materials were preferentially selected for both blade flaking and the manufacture of formal flaked tools. This is presumably because high-quality materials have good flaking properties that assure a reduced failure rate when producing blades and elongated flake blanks, as well as secondary retouch. It is therefore legitimately hypothesized that, when available, EUP hunter-gatherers would favor high-quality materials to make formal flaked tools. To further examine this pattern, I attempt to delineate diachronic trends of change in the selection of lithic raw materials, core reductions (mainly on blade technology), and formal tool production during contiguous phases of the EUP on the Musashino Upland (i.e., Period I).

\section{Period I}

In Period I, both the frequency of obsidian use and formal flaked tool production were quite low, and most of (unmodified) flake tools and core were made from locally available low-quality chert. This may indicate that EUP hunter-gatherers did not have a preference for "high-quality" lithic raw materials in this earliest period. Although blade technology and formal flaked tools were present, they are only sporadically found in assemblages. The mean weights of lithic artifacts in the assemblages are heavier than those of later periods. These patterns suggest the possibility that unmodified flakes and core tools containing adzes were the dominant lithic tools in this period. Groups of hunter-gatherers on the Musashino Upland during Period I preferentially employed generalized core reductions, coupled with frequent use of locally available materials.

\section{Period II}

The percentage of obsidian in Period II is higher than that of Period I and highquality lithic raw materials were more frequently utilized. Formal flaked tools and blade blank tools are more commonly found in the assemblages of Period II than those of Period I, while refitted specimens including blades are as few as those of Period I. 


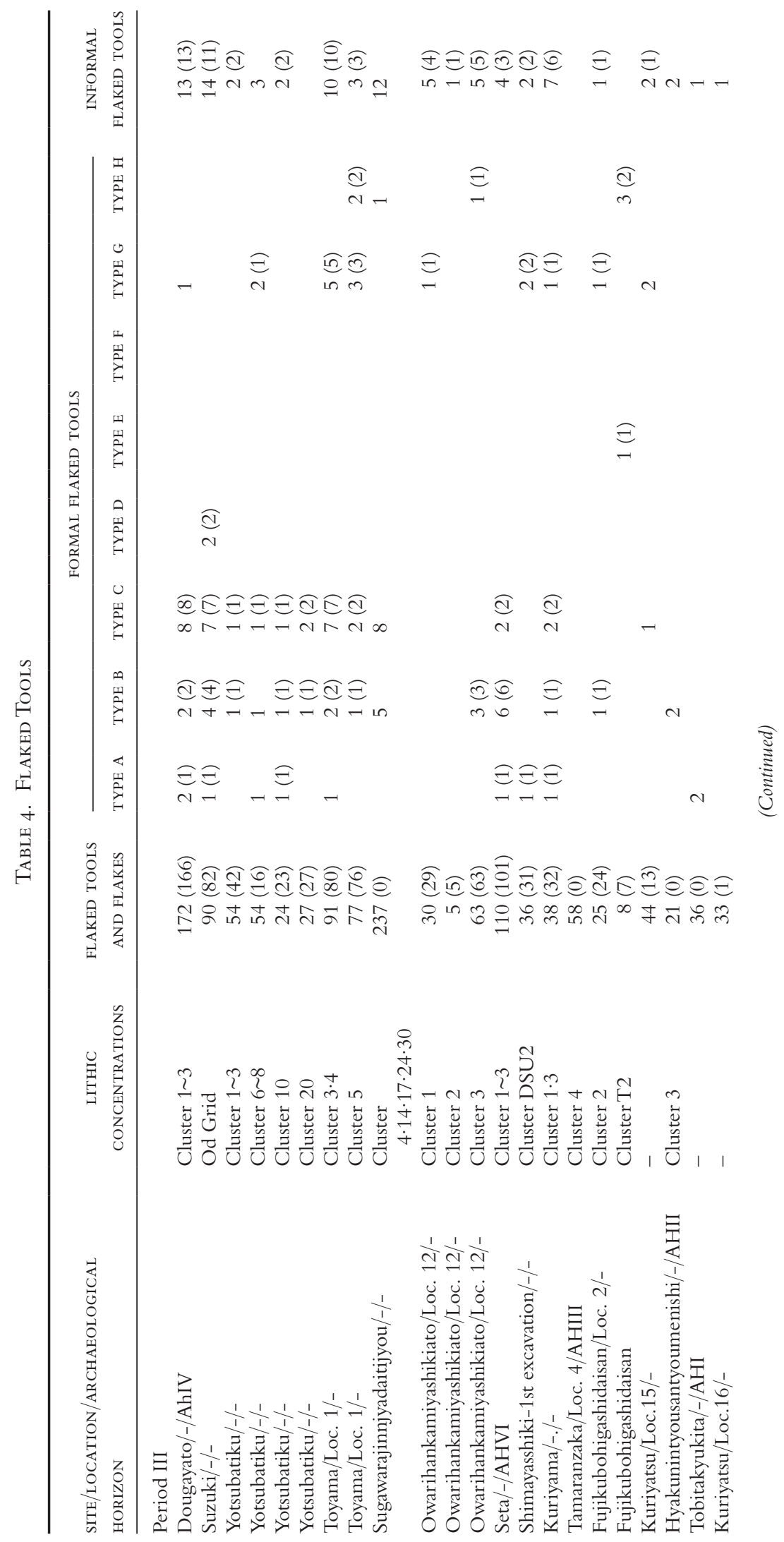




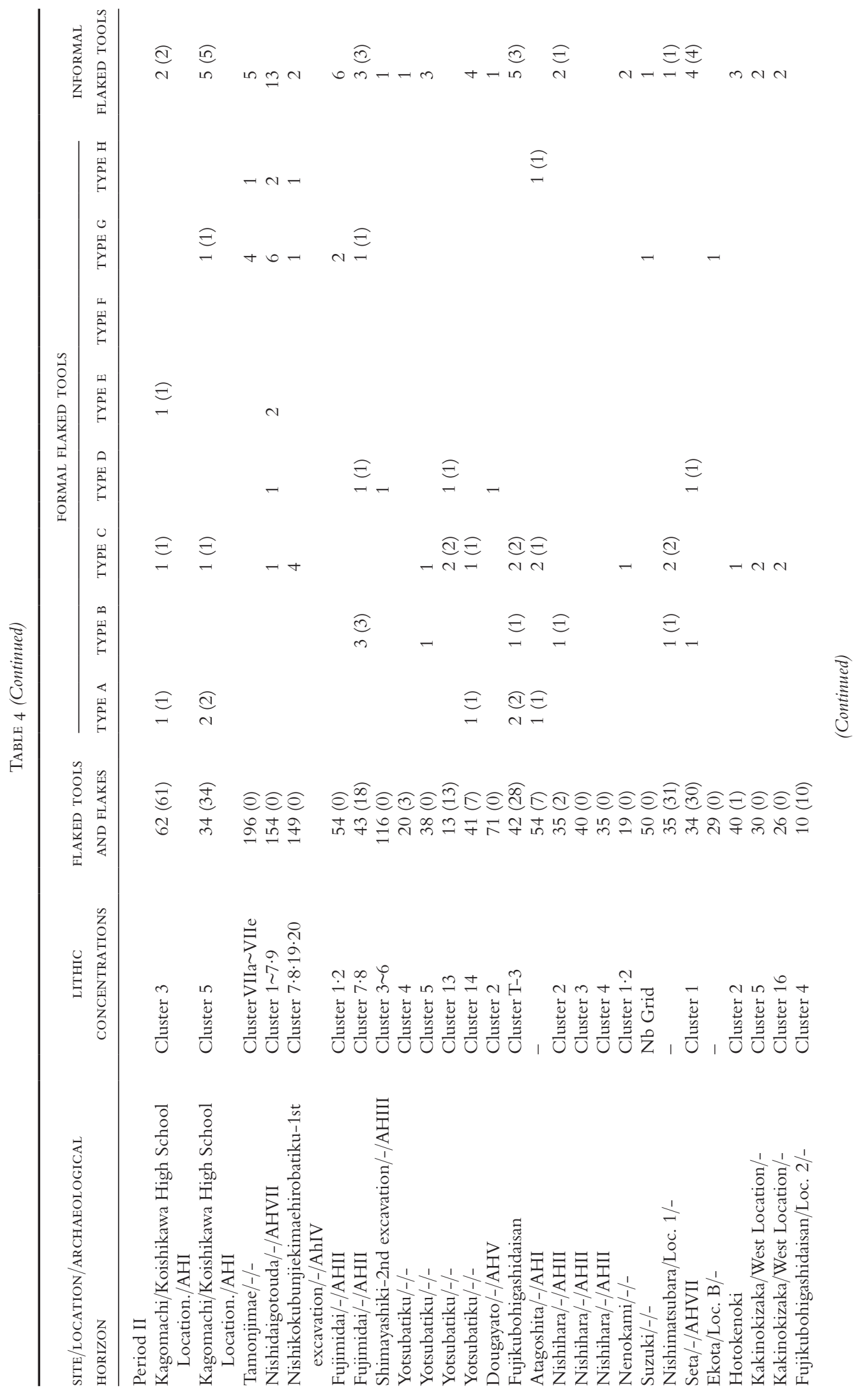




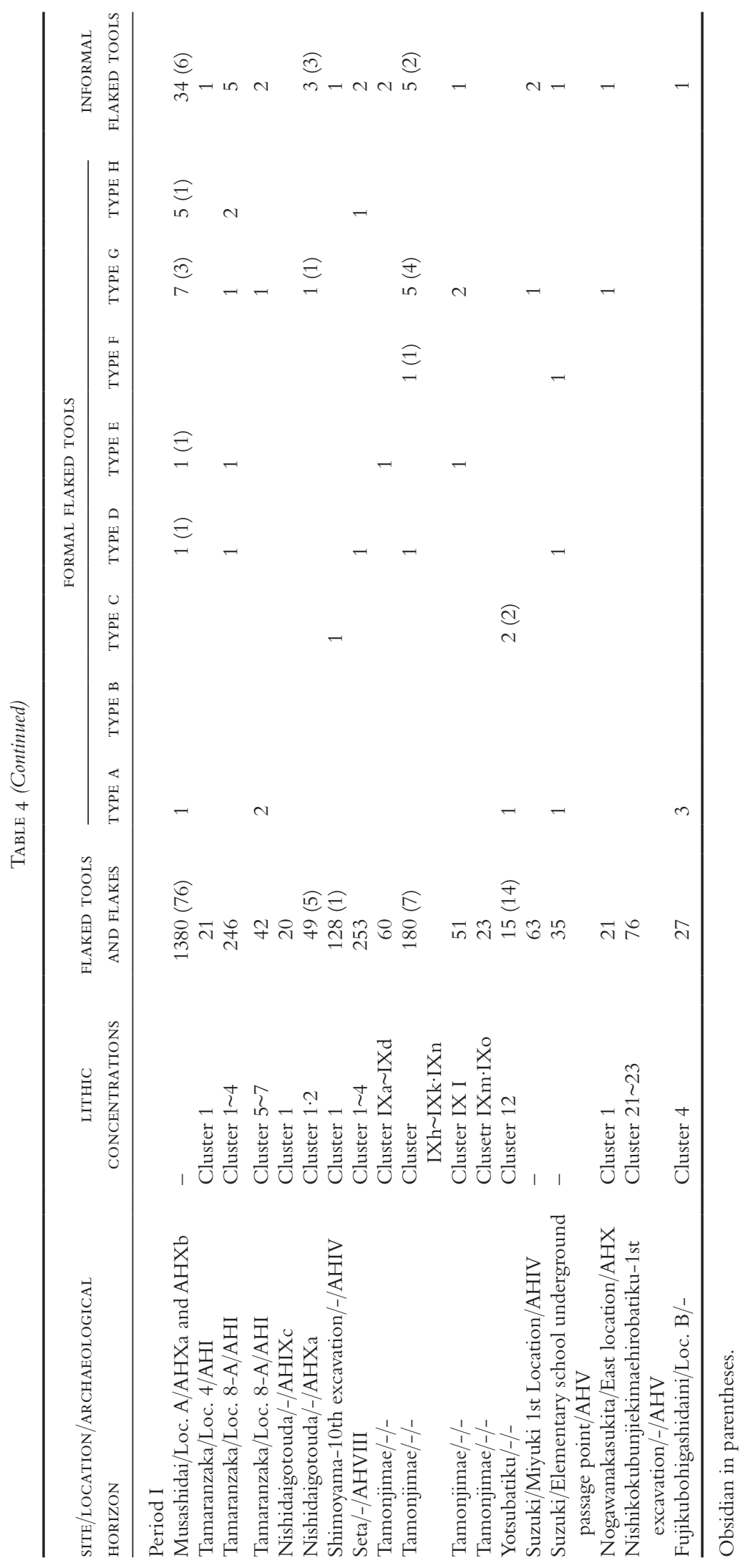


Table 5. The Frequency of Formal and Informal Flaked Tools

\begin{tabular}{|c|c|c|c|c|c|c|}
\hline \multirow{2}{*}{$\begin{array}{l}\text { LITHIC } \\
\text { CONCENTRATIONS }\end{array}$} & \multicolumn{3}{|c|}{ FORMAL FLAKED TOOLS } & \multicolumn{3}{|c|}{ INFORMAL FLAKED TOOLS } \\
\hline & ALL & OBSIDIAN & OTHER & ALL & OBSIDIAN & OTHER \\
\hline \multicolumn{7}{|l|}{ Period III } \\
\hline Mean & $9.8 \%$ & $10.7 \%$ & $9.5 \%$ & $6.8 \%$ & $6.9 \%$ & $10.4 \%$ \\
\hline Total & $8.5 \%$ & $10.4 \%$ & $5.4 \%$ & $6.8 \%$ & $7.8 \%$ & $5.0 \%$ \\
\hline \multicolumn{7}{|l|}{ Period II } \\
\hline Mean & $5.3 \%$ & $15.1 \%$ & $3.1 \%$ & $5.5 \%$ & $9.2 \%$ & $4.3 \%$ \\
\hline Total & $4.1 \%$ & $10.1 \%$ & $2.7 \%$ & $4.9 \%$ & $10.5 \%$ & $3.7 \%$ \\
\hline \multicolumn{7}{|l|}{ Period I } \\
\hline Mean & $4.0 \%$ & $22.7 \%$ & $8.1 \%$ & $2.5 \%$ & $19.3 \%$ & $2.1 \%$ \\
\hline Total & $1.8 \%$ & $13.6 \%$ & $1.4 \%$ & $2.3 \%$ & $10.7 \%$ & $1.9 \%$ \\
\hline
\end{tabular}

Because of these characteristics, Period II is regarded as a transitional phase between Period I and Period III.

\section{Period III}

In Period III, the frequency of obsidian use was highest among all of the periods, and most of the lithic raw materials are high quality (e.g., hard shale). These patterns indicate that high-quality lithic raw materials were commonly chosen in the Period III assemblages, and sometimes in large amounts. Blade technology became more frequent in refitted specimens, and blade blanks are more often found in flaked tools. In addition, the frequency of formal flaked tools is high. These characteristics of the assemblages - frequent use of blades and high-quality materials - imply that production and use of formal flaked tools came to be more critical for hunter-gatherer lifeways during Period III compared to previous periods.

The observed changes in relationships between tool blank productions and raw material uses from Period I to Period III are not interpreted as a simple scheme of technological development (i.e., increased sophistication and proliferation of blade technology and methods of formal tool production), but likely reflect drastic changes in the purpose and the manner of lithic raw material utilization. Because the selection of lithic raw materials, forms of core reductions, and formal tool production all changed simultaneously, there were several criteria for lithic raw material selection that varied through the several phases of the EUP on the Musashino Upland. The exclusive use of high-quality materials for making blades and formal flaked tools is consistently found in the EUP, suggesting that high-quality materials were selected for carrying out similar tasks. This is opposed to the interpretation that it was changes in technological capabilities that allowed EUP artisans to make particular blank types and tools. The assemblages of Phase I show unusual characteristics, with abundant use of unmodified flakes and core tools made from local materials, which contrast with the Upper Palaeolithic record in other regions of Eurasia. Therefore, characteristics of these EUP assemblages indicate that variability and diversity in lithic raw material use and core reductions within each organizational technology was present during the EUP.

The changes in lithic material use could be explained by transformations in the scale of foraging territories and residential mobility. Many studies suggest that human 


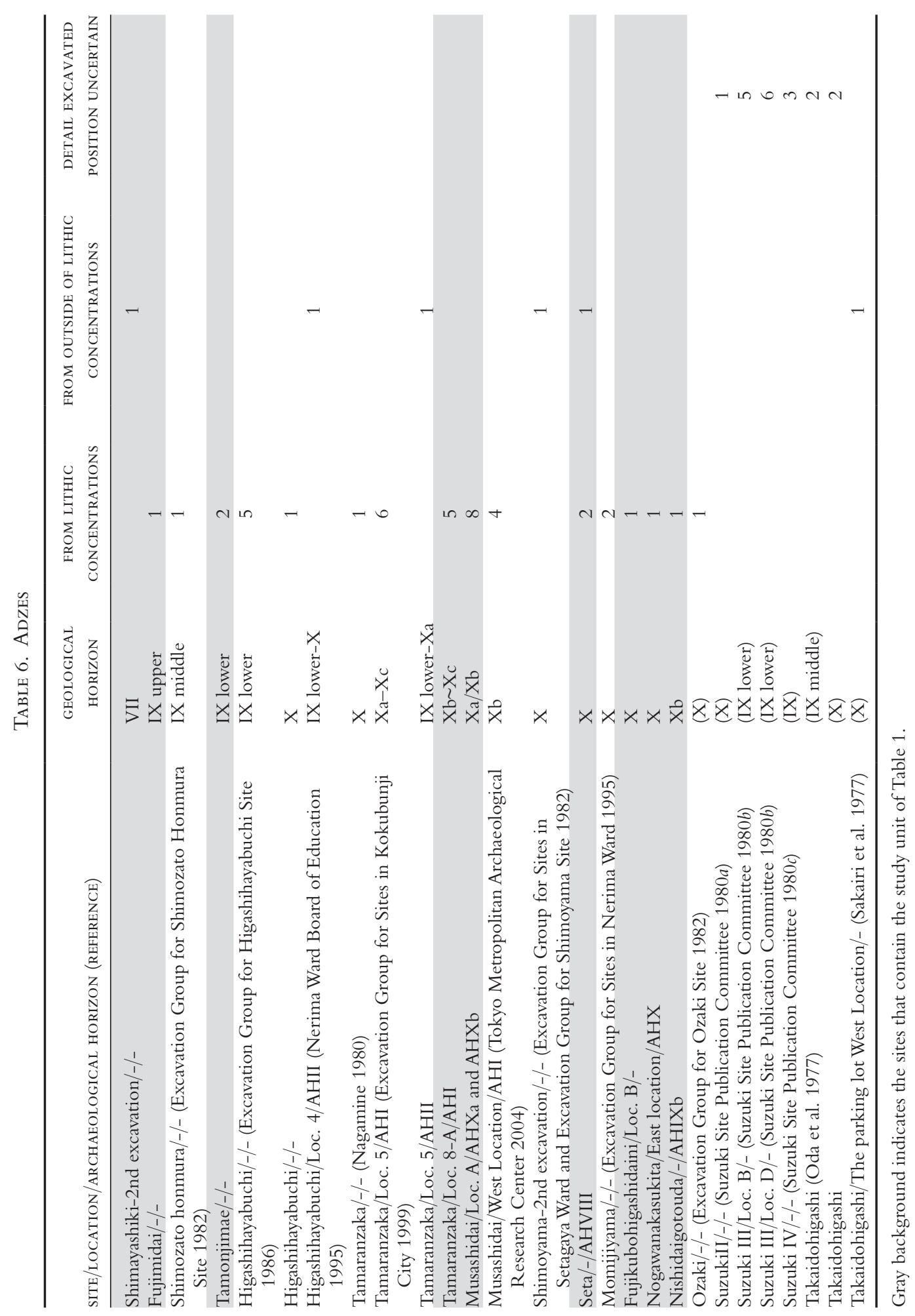


foraging territory expanded during Period III, based on the presence of considerable amounts of obsidian from Shinshu, a few hundred kilometers away from the Musashino Upland (Ishimura 2002; Ito 1998; Kanayama 1990; Maji 2003; Suwama 1998; Tamura 1992; Yoshikawa 2003).

In Palaeolithic research in the Japanese islands, the procurement strategies for lithic raw materials have been discussed by a number of researchers. Both hypotheses of direct procurement of lithic raw materials (Ono 1975) and procurement of these materials through exchange (Harunari 1976) were presented in the beginning of this discussion. Recently, most researchers seem to model procurement strategies from the assumption of an "embedded strategy" (Binford 1979). However, no data has been obtained to discuss specific foraging routes between obsidian provenance areas and sites on the Musashino Upland. At the present stage of research, we don't have any direct evidence to resolve the issue of how lithic raw materials were procured. Therefore, in this paper I point out only a possibility of relative differences in the scale of foraging territories between periods I and III. In addition, the increasing reliance on obsidian for flaked tools between periods I and III is clearly demonstrated in this current research. Given the observations of frequent use of blade technology and lighter formal flaked tools in the assemblages of Period III, it is possible that the residential mobility of foraging groups increased during Period III (Andrefsky 1998:213214).

In addition to changes in foraging territorial scale and residential mobility, changes in lithic material use could have been related to some changes in the utilization of technologies associated with organic raw material (while not archaeologically visible, presumably existing), possibly in response to changes in the environmental setting (Yamaoka 2004). As opposed to abundant occurrences of formal flaked tools and blade technology during Period III, which are ubiquitously found among Japanese later Upper Palaeolithic assemblages, unmodified flakes and core tools containing adzes dominate the assemblages of Period I. As noted before, these initial EUP assemblages are regarded as unusual in comparison to lithic assemblages of the same period elsewhere in the world. However, the tool assemblages of the initial EUP appear somewhat similar to Pleistocene date assemblages of Southeast Asia, where it is thought that informal lithic tools were frequently utilized for producing perishable tools (Hutterer 1976). Use-wear analysis of adzes shows that they functioned to perform multiple tasks, including hide scraping and woodcutting (Tsutsumi 2006). In addition, evidence of breakage patterns suggests that large adzes could have been used for heavyduty tasks (Sato 2006). Thus, the most probable use of the larger adzes would have been for clearing the forest and woodworking (Tsutsumi 2006).

Paleoenvironmental data seem to supports the possibility of some significant changes in organic raw materials available during the EUP in this region. In the Kanto Region where the present EUP sites are located, analysis of pollen spectrum and evidence of plant fossils show the occurrence of a vegetational change from broad-leaved deciduous forest to coniferous forest toward the onset of the Last Glacial Maximum (Ito 1984; Tsuji and Kosugi 1991). This shift of forest types roughly corresponds with the transition from Period I to Period III. In addition, opal phytolith analysis shows that grassland vegetation was causal in creating the Black Band II (strata VII-IX: buried paleosol) in the Tachikawa Loam (Sase et al. 2008). The expansion of grassland vegetation from Stratum X to Black Band II (strata VII-IX) roughly corresponds with a decrease of adzes. 


\section{CONCLUSION}

The present article discusses changes in EUP lithic assemblages on the Musashino Upland in terms of core reductions, selection of lithic raw materials, and formal tool productions. The results suggest that changes in aspects of lithic assemblage variability could be explained by changes in the scale of foraging territory and technological organization during the Early Upper Palaeolithic. In future research, comparative data from the other regions are required to clarify relationships between variation in lithic material use and hunter-gather mobility strategies.

\section{ACKNOWLEDGMENTS}

I thank Dr. Yuichi Nakazawa and Prof. Laura Junker for their helpful support with this paper and revising my troubled English. All errors, however, are my responsibility.

\section{REFERENCES CITED}

Akazawa, Takeru, Shizuo Oda, and Ichiro Yamanaka

1980 The Japanese Paleolithic: A Techno-typological Study. Tokyo: Rippushobo (in Japanese and English).

ANDREFSKY, WiLliam, JR.

1998 Lithics: Macroscopic Approaches to Analysis. Cambridge: Cambridge University Press.

Aoki, KaOri, AND Fusao Arai

2000 Late Quaternary tephrostratigraphy of marine core KH94-3, LM-8 off Sanriku, Japan. The Quaternary Research 39-2:107-120 (in Japanese with English abstract).

BINFORD, LEWIS R.

1979 Organization and formation processes: Looking at curated technologies. Journal of Anthropological Research $25: 255-273$.

Dougayato Site 32nd Excavation Group

2001 Dougayato Site V. Setagaya Ward Board of Education (in Japanese).

Excavation Group for Higashihayabuchi Site

1986 Higashihayabuchi Site (in Japanese).

Excavation Group for Itabashi Ward Yotsubachiku Site

1996 Yotsubachiku Site (in Japanese).

Excavation Group for Itabashi-ku Narimasutonoyama Site

1992 Narimasutonoyama Site (in Japanese).

Excavation Group for Nenokami Site

1988 The Excavation Report of Nenokami Site (in Japanese).

Excavation Group for Nishihara Site

1993 Nishihara Site (in Japanese).

Excavation Group for Ozaki Site

1982 Ozaki Site. Nerima Ward Board of Education (in Japanese).

Excavation Group for Shimozato Honmura Site

1982 Shimozato Honmura Site (in Japanese).

Excavation Group for Shinjyuku Ward Hyakunintyou Site

1997 Hyakunintyousantyoumenishi Site III (in Japanese).

Excavation Group for Sites in Setagaya Ward

1982 Karuta Site, Kinuta Junior High School VII Tumulus. Setagaya Ward Board of Education (in Japanese).

Excavation Group for Sites in Setagaya Ward and Excavation Group for Shimoyama Site

1982 Shimoyama Site I. Setagaya Ward Board of Education (in Japanese).

Excavation Group for Sites in Koganei City

1989 Nogawanakasukita Site (in Japanese). 
Excavation Group for Sites in Kokubunji City

1984 Suzuki Site V (in Japanese).

1997 Tamaranzaka Site II (in Japanese).

1999 Tamaranzaka Site III (in Japanese).

2003a Excavation Report of Musashi Provincial Monastery Site 29 (in Japanese).

2003 Tamaranzaka Site IV (in Japanese).

Excavation Group for Sites in Nerima Ward

1992 The Excavation Report of Atagoshita Site (in Japanese).

1995 Momijiyama Site I (in Japanese).

Excavation Group for Sites in Tokyo Metropolitan Futyu Hospital

1984 Musashidai I (in Japanese).

Excavation Group for Tamonjimae Site

1983 Tamonjimae Site II (in Japanese).

Excavation Group for Tokyo Metropolitan Schools

1999 Fujimidai Site (in Japanese with English summary).

2000 Kagomachi Site (in Japanese).

Excavation Group for Toyama Site

1999 Nerima Ward Toyama Site Loc. 1 and Loc. 2 (in Japanese).

Fujiwara, Hitoshi

1983 Technological bases of Upper Paleolithic in Tohoku region-mainly the blade assemblages. Koukogaku-Ronsou. Tohoku University Archaeology Laboratory: 63-91 (in Japanese).

Harunari, Hideji

1976 Innovative changes between Paleolithic and Jomon period. Quarterly of Archaeological Studies 22-4: 68-92 (in Japanese).

Hidai, TAMiKo, ED.

2000 Terracing in the Basin of the Tama River and Environment of Archaeological Site Location. Tokyo: Tokyu Kankyo Joka Zaidan (in Japanese).

HutTerer, KARL

1976 An evolutionary approach to the Southeast Asia cultural sequence. Current Anthropology 17:221-242.

INADA, TAKASHI

1984 Choice and procurement system of stone materials from the Musashino upland in the Palaeolithic. Quarterly of Archaeological Studies 30-4:17-37 (in Japanese).

IsHimura, TOMO

2002 The structure of human groups under the AT Volcanic climate-The comprehension of the industry of layerVI of Musashino Plateau. Tokyo Koko 20:1-20 (in Japanese).

Iто, FujIO

1984 Environmental changes and lithic industries in Tachikawa Loam on Musashino Upland. Arcaeology in Musashino: 31-44 (in Japanese).

Ito, Tsuyoshi

1998 Assemblages from Layer VI-Compositions of lithic artifacts and social form. Sekkinimanabu $1: 2-18$ (in Japanese).

Japan Association for Quaternary Research

$2000 \quad{ }^{14}$ C Ages of the Japanese Prehistory (in Japanese).

Kaizuka, Sohei, Kazuyuki Koike, Kunihiro Endo, Haruo Yamazaki, and Takehiko Suzuki, ed. 2000 Geomorphology of Kanto and Izu-Ogasawara. Vol. 4 of Regional Geomorphology of the Japanese Islands. Tokyo: University of Tokyo Press (in Japanese).

KAKUBARI, JUNICHI

1991 Dynamism between sites around obsidian sources and consuming sites-Behavioural comprehension of Upper Paleolithic assemblages. Senshikokogakuronsyu 1:25-82 (in Japanese).

Kakubari, Junichi, and Hirokazu Fujinami

1986 Observations concerning the lithic component from levels 6-9 of the Musashino Tableland, Tokyo. Tokyo Koko 4:1-16 (in Japanese).

1987 A Memorandum on the Lithic Blade Technique. Tokyo Koko 5:1-18 (in Japanese). 
Kanayama, Yoshiaki

1990 The obsidian stone tool assemblage in the period of Aira Tanzawa Pumice. Memoir of the Museum of Archaeology Kokugakuin University 6:1-16 (in Japanese with English abstract).

Kato, Yuji, and Masakatsu Toda

1982 Suzuki Site Miyuki 1st Location. Excavation group for sites in Kodaira City (in Japanese).

Lithic INDUSTRY STUdy Society, ED.

1991 The Study of Lithic Industry 3 (in Japanese).

Machida, Hiroshi

2005 A tephrochronological review on the earlier Paleolithic archaeological remains in South Kanto. Palaeolithic Research 1:7-16 (in Japanese with English abstract).

Maji, Koyo

2003 Patterns of the Late Paleolithic mobile life in Japan: Evidence from obsidian distribution in southern Kanto region. Quarterly of Archaeological Studies 50-1:35-55 (in Japanese with English abstract).

Mitaka City Board of Education and Excavation Group for the Sites in Mitaka City

1996 Hanezawadai Site (in Japanese).

1997 Shimayashiki Site (in Japanese).

Miyoshi Town BoARd of Education

1987 Excavation Report of Fujikubohigashidaisan Site (in Japanese).

1988 Excavation Report of the Sites in Miyoshi Town (in Japanese).

1991 Excavation Report of Fujikubohigashidaisan Site Loc. 2 (in Japanese).

Nagamine, Kouichi

1980 Tamaranzaka Site. Kokubunji City Board of Education (in Japanese).

Nakano Ward Board of Education and Excavation Group for the Sites in Old National

SANATORIUM NAKANO HOSPITAL

1999 Excavation Report of Ekota Site I (in Japanese).

Nerima Ward BoArd of Education

1995 Higashihayabuchi Site Loc. 4 (in Japanese).

Nerima Ward Board of Education and Excavation Group for the Sites in Nerima Ward 1987 Kuriyama Site (in Japanese).

Oda, Shizuo, Fujio Ito, Chales T. Keally, and Yutaka Shigezumi

1977 Takaidohigashi Site. Excavation Group for Takaidohigashi Site (in Japanese with English summary).

OKumura, Yoshinobu

1987 Development of the blade technology. Ohiradaishisou 6:13-31 (in Japanese).

ONO, AKIRA

1975 Note about transportation of lithic raw material in Paleolithic. Quarterly of Archaeological Studies 21-4:17-19 (in Japanese).

OrIKASA, AKIRA

1989 Chapter 4, The outline and issues of assemblages from Kuriyatsu Loc. 14, Loc. 15 and Loc. 16, in The Site Group in Fujimi City VII. Fujimi City Board of Education (in Japanese).

Saitama Cultural Deposits Research Corporation

1994 Hananoki, Mukaihara, Kakinokizaka, Mzukubo, Maruyamadai (in Japanese).

SAKairi, TAmiko, Fujio Ito, and Akira Orikasa

1977 Takaidohigashi Site Parking West Location (in Japanese).

SASAKI, YASUTOSHI

1977 Nishimatsubara Loc. 1, in The Report of Cultural Property in Fujimi City. Fujimi City Board of Education (in Japanese).

Sase, Takashi, Hiroshi Machida, and Mamoru Hosono

2008 Fluctuations of opal phytolith assemblage in the Tachikawa and Musashino Loam formations in southwest Kanto, central Japan: Change in vegetation, climate, terrace, and soilfacies since marine isotope stage 5.1. The Quaternary Research 47(1):1-14 (in Japanese with English abstract).

SATO, Hiroyuki

1992 Structure and Evolution of Japanese Paleolithic Culture. Tokyo: Kashiwa-Shobo (in Japanese). 
2006 Socio-ecological research of the circular ettlements in Japanese Early Upper Paleolithic. Paleolithic Research 2:47-54 (in Japanese with English abstract).

Second Excavation Group for the Sites in Tokyo Metropolitan and Excavation Group for NishidAi SiTE

1999 Excavation Report of Nishidaigotouda Site Loc. 1 (in Japanese).

Seta Site 11th Excavation Group

1997 Seta Site II. Setagaya Ward Board of Education (in Japanese).

Shimoyama Site 10th Excavation Group

2002 Shimoyama Site IV. Setagaya Ward Board of Education (in Japanese).

SUWAMA, JuN

1998 Lithic raw materials on the Sagamino Upland during the period of the eruption of AT. Rettou no kokogaku: 301-315.

Suzuki Site Publication Committee

1978 Suzuki Site I (in Japanese).

1980 a Suzuki site II (in Japanese).

1980 buzuki site III (in Japanese).

1980c Suzuki site IV (in Japanese).

TAMURA, TAKASHI

1992 Far mountain, black stone-A socio-ecological consideration of Phase II assemblages on the Musashino Upland. Senshikokogakuronsyu 2:1-46 (in Japanese).

Toda, Masakatsu, and Excavation Group for Suzuki Site

1976 Stone axes from Suzuki site (Kodaira city, Tokyo). Quarterly of Archaeological Studies 23-3: 93105.

Tokyo Metropolitan Archaeological Research Center

1992 Tobitakyukita Site (in Japanese).

1997 Sugawarajinjyadaichiue Site (in Japanese).

1998 Shimayashiki Site (in Japanese).

2002 Excavation Report of Owarihankamiyashikiato Site X (in Japanese).

2004 The Site in Relation with Musashi Provincial Monastery Site (Musashidai West Location) (in Japanese).

Tsuji, Sei-IChiro, and Masato Kosugi

1991 Influence of Aira-Tn ash (AT) eruption on ecosystem. The Quaternary Research 30(5) : 419-426 (in Japanese with English abstract).

TSUTSUMi, TAKASHi

2006 Thinking about functions of stone axes during Early Upper Paleolithic-Usewear analysis of stone axes from Hinatabayashi B site. Journal of Nagano Prefecture Archaeological Society 118:1-12 (in Japanese).

\section{WAKo City BoARd of Education}

2002 Excavation Report of the Sites in Wako City (in Japanese).

YАMAOKA, TAKUYA

2004 Innovation of lithic raw material utilization during the Upper Paleolithic in the Musashino plateau. Quarterly of Archaeological Studies 51-3:12-31 (in Japanese with English abstract).

2006 an innovative process of lithic raw material utilization during the Early Upper Paleolithic on the Musashino Upland. Cultura Antigua 58-III : 107-125 (in Japanese with English abstract).

$2006 b$ Current issues in the study of the Early Upper Paleolithic in Musashino Upland, Tokyo. Current Research in the Pleistocene 23:37-39.

\section{YOSHIKAWA, KOTARO}

2003 The phase of "the VIth layer stage" of the Tachikawa loam in southern Kanto region. Paleolithic Archaeology 64 : 43-50 (in Japanese with English abstract).

\section{ABSTRACT}

This article explains lithic assemblage transitions during the Early Upper Palaeolithic (EUP) on the Musashino Upland by quantitative comparisons of lithic raw materials, core reduction (blade technology), and formal tool production. The results suggest that 
changes in aspects of lithic assemblage variability could be explained by changes in raw material utilization, not developments (sophistication of tool-making skills) in blade technology and methods of formal tool production. The results also indicate the possibility that the changes in lithic raw material would have been affected by changes in residential mobility and the foraging territorial scale of EUP hunter-gatherers, as well as the changes in organic raw material utilization in whole technological organization in various environmental settings during the EUP. Beside them, the characteristics of the lithic assemblages in Period I as the initial EUP assemblages in this region are different from general characteristics of Upper Palaeolithic assemblages (blade technology, standardized and formal flaked tools) in Eurasia. The nature of lithic raw material utilization, especially flaked tool use, in Period I assemblages looks extremely expedient. Therefore, the characteristics of initial EUP assemblages in this region represent that diversity in lithic raw material utilization and technological organization was present during the EUP. KeYwords: the Early Upper Palaeolithic (EUP), Japan, the Musashino Upland, stone tools, raw material, foragers. 